Pontifícia Universidade $C_{\text {atólica }}$

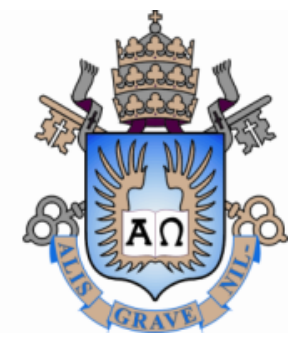

Jose Carlos Solis Tito

Análise Numérica de Escavações Profundas em Solo

Dissertação de Mestrado

Dissertação apresentada como requisito parcial para obtenção do grau de Mestre pelo Programa de Pós-graduação em Engenharia Civil da PUC-Rio.

Orientador: Prof. Celso Romanel

Rio de Janeiro

Junho de 2014 


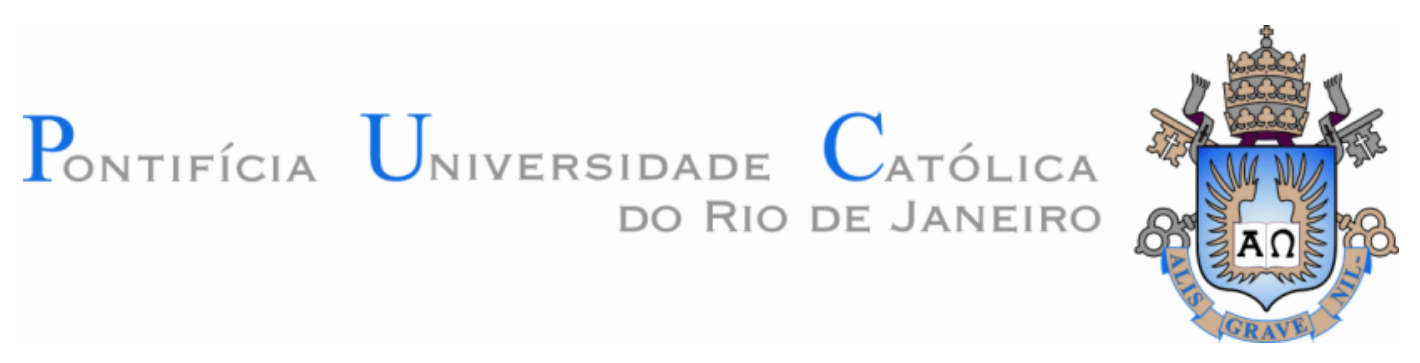

Jose Carlos Solis Tito

\section{Análise Numérica de Escavações Profundas em Solo}

Dissertação apresentada como requisito parcial para obtenção do grau de Mestre pelo Programa de PósGraduação em Engenharia Civil do Departamento de Engenharia Civil do Centro Técnico Científico da PUCRio. Aprovada pela Comissão Examinadora abaixo assinada.

Prof. Celso Romanel

Orientador

Departamento de Engenharia Civil - PUC-Rio

Prof. Pedricto Rocha Filho

Departamento de Engenharia Civil - PUC-Rio

Prof ${ }^{a}$. Bernadete Ragoni Danziger Universidade do Estado do Rio de Janeiro

$D^{\mathrm{a}}$. Jackeline Rosemery Castañeda Huertas

Departamento de Engenharia Civil - PUC-Rio

Prof. José Eugenio Leal

Coordenador Setorial do Centro

Técnico Científico - PUC-Rio

Rio de Janeiro, 16 de junho de 2014. 
Todos os direitos reservados. É proibida a reprodução total ou parcial do trabalho sem autorização da universidade, do autor e do orientador.

\section{Jose Carlos Solis Tito}

Graduou-se em Engenharia Civil no Departamento de Engenharia Civil da UNSAAC (Universidad Nacional de San Antonio Abad del Cusco - Peru) em 2010. Em 2012 iniciou o curso de Mestrado em Engenharia Civil na PUC-RIO, na área de Geotecnia, atuando na linha de pesquisa de Geomecânica Computacional.

Ficha Catalográfica

Tito, Jose Carlos Solis

Análise numérica de escavações profundas em solo / Jose Carlos Solis Tito ; orientador: Celso Romanel. - 2014.

189 f.: il. (color.) ; $30 \mathrm{~cm}$

Dissertação (mestrado)-Pontifícia Universidade Católica do Rio de Janeiro, Departamento de Engenharia Civil, 2014.

Inclui bibliografia

1. Engenharia civil - Teses. 2. Escavação profunda. 3. Validação de análise. 4. Análise numérica de escavação. I. Romanel, Celso. II. Pontifícia Universidade Católica do Rio de Janeiro. Departamento de Engenharia Civil. III. Título.

CDD: 624 
Aos meus pais Ignácio e Elsa, pelo amor, apoio e incentivo que me ofereceram em todos momentos. À minha irmã Edith pela ajuda que sempre me ofereceu. 


\section{Agradecimentos}

Ao meu orientador Professor Celso Romanel pela orientação, confiança, conhecimento transmitido e sua disposição prestada na orientação deste trabalho.

Ao programa de CAPES e à PUC-Rio, pelo apoio concedido, que viabilizou a realização deste trabalho.

Aos professores do curso de Mestrado em Engenharia Civil da PUC-Rio, pelos ensinamentos transmitidos em cada uma das disciplinas que cursei.

Aos professores da UNSAAC, pelos ensinamentos da engenharia transmitidos durante a graduação.

Aos meus pais e irmã, pela educação e carinho de todas as horas.

A todos os amigos e familiares, que de uma forma ou de outra me ajudaram. 


\section{Resumo}

Tito, Jose Carlos Solis; Romanel, Celso. Análise Numérica de Escavações Profundas em Solo. Rio de Janeiro, 2014. 189p. Dissertação de Mestrado Departamento de Engenharia Civil, Pontifícia Universidade Católica do Rio de Janeiro.

$\mathrm{Na}$ atualidade, devido à necessidade de realizar obras de engenharia de grande porte em ambiente urbano, o engenheiro defronta-se muitas vezes com o desafio de executar escavações profundas, as quais devem ser projetadas para serem estáveis e limitar deformações a níveis aceitáveis. Uma escavação profunda estável é aquela cujas paredes não colapsam e o seu fundo não experimenta levantamento descontrolado. Deformações do solo podem afetar construções vizinhas, vias urbanas e outras instalações públicas, com consequências que dependem tanto da magnitude quanto do padrão do movimento do solo ao redor da escavação. A previsão do comportamento de uma escavação profunda envolve análises tanto de estabilidade quanto de deformação. Análises de estabilidade podem em geral ser feitas através de métodos de equilíbrio limite, mas as análises de deformações, por outro lado, são mais difíceis de serem previstas, necessitando do auxilio de métodos numéricos. Nesta dissertação, o comportamento de escavações profundas é investigado numericamente pelo método de elementos finitos, com especial atenção à ocorrência de deformações, para cuja previsão requer-se a utilização de modelos constitutivos que representem muitos dos aspectos de comportamento de solos reais.

\section{Palavras-chave}

Escavação profunda; validação de análise; análise numérica de escavação. 


\section{Abstract}

Tito, Jose Carlos Solis; Romanel, Celso (Advisor). Numerical Analysis of Deep Excavations in Soil. Rio de Janeiro, 2014. 189p. MSc. Dissertation Departamento de Engenharia Civil, Pontifícia Universidade Católica do Rio de Janeiro.

At the present, due to the need for engineering works of large scale in urban environment, the engineer is confronted often with the challenge of performing deep excavations, which should be designed to be stable and with acceptable levels of deformations. A stable deep excavation is that, whose walls do not collapse and its base does not experience uncontrolled heave. Soil deformations can affect neighboring buildings, urban roads and other public facilities, with consequences that depend on both the magnitude and the pattern of the movement of the soil around the excavation. The prediction of the behavior of a deep excavation therefore involves stability analysis as well as deformation analysis. Stability analysis can generally be made through limit equilibrium methods, but deformation analyses are more difficult to predict, requiring the assistance of numerical methods. In this dissertation the behavior of deep excavations is numerically investigated by the finite element method, with special attention to the occurrence of deformations, for this prediction requires the use of constitutive models that represent many aspects of behavior of real soils.

\section{Keywords}

Deep excavation; validation of analysis; numerical analysis of excavation. 


\section{Sumário}

1. Introdução 27

2. Escavações profundas 32

2.1. Sistemas de contenção 32

2.2. Deslocamentos em escavações 42

2.2.1. Procedimentos semi-empíricos 43

2.2.2. Aplicação do método dos elementos finitos (MEF) 54

3. Aspectos Metodológicos 59

3.1. Descrição do projeto de escavação 59

3.2. Parâmetros empregados no modelo constitutivo 78

3.2.1. Correlação dos parâmetros do solo da informação disponível no $\begin{array}{ll}\text { projeto. } & 78\end{array}$

3.2.2. Revisão dos parâmetros dos solos 84

3.2.3. Descrição dos parâmetros empregados no modelo 98

3.2.4. Descrição dos parâmetros dos elementos estruturais 98

3.3. Modelagem de uma escavação 106

3.4. Comportamento tensão-deformação 110

3.4.1. Modelo Mohr Coulomb. 126

3.5. Considerações do modelo 134

4. Análise e apresentação dos resultados. 138

4.1. Análise axisimétrico, em 2D. 138

4.2. Análise em 3D. 139

4.3. Apresentação e discussão de resultados 141

5. Conclusões e Sugestões 166

5.1. Conclusões 166

$\begin{array}{lr}\text { 5.2. Sugestões } & 167\end{array}$ 
6. Referências Bibliográficas

ANEXO 


\section{Lista de figuras}

Figura 2.1 - Sistemas de contenção de escavações profundas com paredes verticais, (Massad, 2005).

Figura 2.2 - Cortina de estacas-pranchas sem ancoragem (Whitlow, 1994).

Figura 2.3 - Cálculo dos fatores de segurança contra levantamento do fundo em solos coesivos: (a) escavação profunda com $H / B>1$, de acordo com Bjerrum e Eide (1956); (b) para escavação superficial ou larga, com $\mathrm{H} / \mathrm{B}<1$, de acordo com Terzaghi (1943), (Puller, 2003).

Figura 2.4 - Determinação do gradiente hidráulico máximo na região do fundo da escavação por rede de fluxo (Puller, 2003)

Figura 2.5 - Penetração necessária da cortina impermeável para evitar ruptura hidráulica em areia densa ou fofa: (a) maciço de profundidade infinita; (b) camada de profundidade finita (Puller, 2003).

Figura 2.6 - Parede de estacas secantes para estacionamento subterrâneo (Rasines e Ramos, 2004).

Figura 2.7 - Processo de execução do método seco escandinavo, (1) posicionamento, (2) penetração/desagregação, (3) penetração até a profundidade do projeto, (4) extração com injeção, (5) coluna completa (Palacio, 2004).

Figura 2.8 - Esquema de execução com o método úmido europeu (Palacio, 2004).

Figura 2.9 - Aplicação da técnica jet-grouting (Pereira, 2008)

Figura 2.10 - Movimentos do terreno associados a escavações profundas (Craig, 2007).

Figura 2.11 - Faixa de variação de $\delta_{\mathrm{H}(\max )} / \mathrm{H}$ em função do coeficiente de segurança $\left(F_{b}\right)$ contra o levantamento do fundo da escavação (Mana e Clough, 1981).

Figura 2.12 - Escavações escoradas: (a) movimento lateral e

(b) recalque da superfície, (Clough et al. 1989).

Figura 2.13 - Método de Clough e O`Rourke (1990) 
Figura 2.14 - Definição das variáveis por Ou et al. (1993) 47

Figura 2.15 - Perfis típicos de recalque, Ou et al. (1993) 47

Figura 2.16 - Relação entre o intervalo de influência aparente e o comprimento da parede, Ou et al. (1993) 48

Figura 2.17 - Relação proposta entre os recalques e a distância da parede para o segundo perfil típico de recalque, Ou et al. (1993) 49

Figura 2.18 - Tipos de perfis de recalque, Hsieh e Ou (1998) 49

Figura 2.19 - Método proposto para a previsão do perfil de recalques do tipo "spandrel". (Hsieh e Ou, 1998). 50

Figura 2.20 - Proposta de Hsieh e Ou (1998) para o perfil do tipo côncavo.

Figura 2.21 - Áreas das componentes em balanço e profunda (Hsieh e Ou, 1998)

Figura 2.22 - Relação entre as áreas As e Ac (Hsieh e Ou, 1998) 52

Figura 2.23 - Relação entre o valor máximo de deslocamento horizontal da parede e o recalque superficial máximo (Hsieh e Ou, 1998)

Figura 2.24 - Deslocamento lateral de uma cortina de estacasprancha e recalques da superfície do terreno (Das, 2001).

Figura 3.1 - Plano em planta de localização do poço 39 pertencente ao Sistema de Coletores Troncos do Sistema Alegria.

Figura 3.2 - Perfil geológico que atravessa o coletor tronco do sistema alegria, no setor do Poço 39.

Figura 3.3 - Perfil geotécnico das seções transversais geotécnicas, a Secção AA está constituída pelas sondagens SP-58, SP-59, SP-60A, SP-61. A Secção BB está constituída pelas sondagens SP-59 e SP-30. 63 Figura 3.4 - Perfil geotécnico do solo para escavação do Poço PS-39. 64 Figura 3.5 - Diagrama do poço PS-39 em planta, onde se mostra a localização dos inclinômetros de controle, dos piezômetros e dos marcos superficiais de recalque.

Figura 3.6 - Diagrama da secção transversal 1-1, onde se mostra a localização do inclinômetro de controle I 01, e do piezômetro de controle PZ3.

Figura 3.7 - Registro dos deslocamentos verticais nos marcos 
superficiais.

Figura 3.8 - Diagrama do inclinômetro empregado para medir os deslocamentos horizontais (Fonte: Projeto).

Figura 3.9 - Registro de deslocamentos horizontais no Inclinômetro I 0169 Figura 3.10 - Registro de deslocamentos horizontais no Inclinômetro 102

Figura 3.11 - Registro de deslocamentos horizontais no Inclinômetro 103

Figura 3.12 - Registro dos deslocamentos horizontais na direção A+, no inclinômetro I 01, do poço de serviço PS-39, correspondente à data da leitura 29 de outubro de 1999.

Figura 3.13 - Registro das leituras piezométricas, determinadas com os piezômetros $\mathrm{PZ1}, \mathrm{PZ2}, \mathrm{PZ3}$.

Figura 3.14 - Diagrama do piezômetro empregado para medir o desenvolvimento das poropressões (Fonte: Projeto).

Figura 3.15 - Leituras de Piezômetro e nível de água (NA) 59, em função das datas de leitura realizadas.

Figura 3.16 - Registro das leituras das cargas totais no piezômetro PZ3, durante o processo de escavação.

75

Figura 3.17 - Diagrama da profundidade do avanço da escavação 77 Figura 3.18 - Relação entre $\mathrm{N}_{\mathrm{SPT}, 60}$ e densidade relativa (Gibbs e Holtz, 1957).

Figura 3.19 - Relação entre $N_{S P T}$ e ângulo de atrito interno (De Mello, 1971).

Figura 3.20 - Relação entre $\mathrm{N}_{\mathrm{SPT}, 60}$ e a resistência não drenada de argilas (U.S. Navy, 1986).

Figura 3.21 - Posição dos nós e pontos de tensão em elementos de placa (Brinkgreve, 2012)

Figura 3.22 - Diagrama de distribuição dos tirantes na laje de jet-grouting no fundo da escavação.

Figura 3.23 - Simulação numérica de escavações via MEF (Zornberg, 1989).

Figura 3.24 - Determinação dos parâmetros de rigidez num ensaio 
triaxial drenado, adaptado de Waterman (2011).

Figura 3.25 - Relação linear entre tensão e deformação para (a)

compressão e (b) cisalhamento de elementos elásticos (Wood, 2004). 112

Figura 3.26 - Trajetória de tensões totais para um ensaio triaxial de compressão convencional, (Wood, 2004).

Figura 3.27 - Propriedades elásticas deduzidas dos estados iniciais de ensaios triaxiais drenados convencionais, (a) plotados em função de deformação distorcional, e (b) plotados em função de deformação axial (Wood, 2004).

Figura 3.28 - Comportamento de materiais ideais perfeitamente plástico (Atkinson, 1993).

Figura 3.29 - Potencial plástico (Atkinson, 1993)

Figura 3.30 - Vetor de deformações plásticas, (Atkinson, 1993)

Figura 3.31 - Modelo elástico- perfeitamente plástico, superfície de escoamento separando regiões elástica e inaccessível do espaço de tensões (Wood, 2004).

Figura 3.32 - Resistência não drenada de acordo com o modelo de Mohr-Coulomb, adaptado de Waterman (2011)

Figura 3.33 - Comportamento do modelo elástico perfeitamente plástico (Brinkgreve, 2012).

Figura 3.34 - Superfície de escoamento no plano de tensões principais, $\mathrm{C}=0$ (Brinkgreve, 2012).

Figura 3.35 - Definição de $E_{0}$ e $E_{50}$ para os resultados de ensaios triaxiais drenados (Brinkgreve, 2012).

Figura 3.36 - (a) Cisalhamento das camadas em estado fofo, (b) cisalhamento de camadas em estado denso, (c) mudança do volume em cisalhamento das camadas em estado fofo e estado denso (Wood, 2004).

Figura 3.37 - Ensaio triaxial drenado com o modelo de Mohr Coulomb, a) Tensão axial contra deformação axial, b) Deformação volumétrica contra deformação axial.

Figura 3.38 - Cálculo do tipo estado permanente disponível no programa PLAXIS 3D 2012.02 para a análise desacoplado das poro 
pressões.

Figura 4.1 - Problema com simetria rotacional (Lizarza, 2011).

Figura 4.2 - Malha deformada no Modelo em 2D, no final do processo de escavação

Figura 4.3 - Elemento tetraedro de dez nós (Lizarza, 2011).

Figura 4.4 - Modelo em 3D, na ultima etapa do processo de escavação.

Figura 4.5 - Deslocamentos totais, nos estágios de escavação,

a) $\left.\left.\left(E_{1}\right) 0.9 \mathrm{~m}, \mathrm{~b}\right)\left(E_{9}\right) 8.6 \mathrm{~m}, \mathrm{c}\right)\left(\mathrm{E}_{18}\right) 16 \mathrm{~m}$.

Figura 4.6 - Sistema geral de coordenadas tridimensional e convenção de sinais para tensões.

Figura 4.7 - Tensão efetiva horizontal, nos estágios de escavação,

a) $\left.\left.\left(E_{1}\right) 0.9 \mathrm{~m}, \mathrm{~b}\right)\left(E_{9}\right) 8.6 \mathrm{~m}, \mathrm{c}\right)\left(E_{18}\right) 16 \mathrm{~m}$.

Figura 4.8 - Evolução de tensão efetiva horizontal do lado ativo e do lado passivo, durante o processo de escavação.

Figura 4.9 - Tensão efetiva vertical, nos estágios de escavação

a) $\left.\left.\left(E_{1}\right) 0.9 \mathrm{~m}, \mathrm{~b}\right)\left(E_{9}\right) 8.6 \mathrm{~m}, \mathrm{c}\right)\left(\mathrm{E}_{18}\right) 16 \mathrm{~m}$.

Figura 4.10 - Poropressões no estado permanente, nos estágios de escavação a) $\left(E_{1}\right) 0.9 \mathrm{~m}$, b) $\left.\left(E_{9}\right) 8.6 \mathrm{~m}, \mathrm{c}\right)\left(E_{18}\right) 16 \mathrm{~m}$.

Figura 4.11 - Evolução da poropressão em estado permanente do lado ativo e do lado passivo.

Figura 4.12 - Excessos de poropressão, em condição permanente, nos estágios de escavação a) $\left.\left.\left(E_{1}\right) 0.9 \mathrm{~m}, \mathrm{~b}\right)\left(E_{9}\right) 8.6 \mathrm{~m}, \mathrm{c}\right)\left(\mathrm{E}_{18}\right) 16 \mathrm{~m} .148$ Figura 4.13 - Evolução do excesso de poropressão do lado ativo. 149

Figura 4.14 - Evolução do excesso de poropressão do lado passivo. 150

Figura 4.15 - Distribuição da carga total (h), nos estágios de escavação a) $\left(E_{1}\right) 0.9 \mathrm{~m}$, b) $\left.\left(E_{9}\right) 8.6 \mathrm{~m}, \mathrm{c}\right)\left(E_{18}\right) 16 \mathrm{~m}$. 150

Figura 4.16 - Perfil de deslocamentos horizontais 152

Figura 4.17 - Descenso do lençol freático no piezômetro de controle PZ3

Figura 4.18 - Comparação dos deslocamentos horizontais empregando os modelamentos usando estado plano de deformações (até uma das etapas iniciais, E4) e tridimensional (até a etapa final, 
E18).

Figura 4.19 - Malha de elementos finitos de escavação de forma retangular, e localização de linhas de controle dos deslocamentos horizontais.

Figura 4.20 - Comparação dos deslocamentos horizontais, das duas linhas de controle consideradas na análise de escavação retangular com a análise tridimensional.

Figura 4.21 - Pontos de tração e pontos de escoamento plástico gerados durante a análise considerando adensamento (correspondente à etapa E8).

Figura 4.22 - Pontos de tração e pontos de escoamento plástico gerados durante a análise plástica (correspondente à etapa E8).

Figura 4.23 - Descenso do nível freático (correspondente às 10 primeiras etapas da análise de adensamento), conforme o avanço da escavação do poço.

Figura 4.24 - Descenso do nível freático (correspondente às 8 ultimas etapas da análise de adensamento), conforme o avanço da escavação do poço.

Figura 4.25 - Descenso do nível freático (correspondente às 10 primeiras etapas da análise plástica), conforme o avanço da escavação do poço.

Figura 4.26 - Descenso do nível freático (correspondente às 8 ultimas etapas da análise plástica), conforme o avanço da escavação do poço.

Figura 4.27 - Evolução dos deslocamentos horizontais na direção A+, ao longo das 18 etapas de escavação, determinados com a análise plástica.

Figura 4.28 - Evolução dos deslocamentos horizontais na direção A+, ao longo das 18 etapas de escavação, determinados com a análise de adensamento.

Figura 4.29 - Evolução do lençol freático, ao longo das 18 etapas de escavação, determinado pelas análises plástica e de adensamento. 


\section{Lista de tabelas}

Tabela 3.1 - Ensaios de recuperação nos piezômetros (permeabilidade in situ), com o piezômetro 59.

Tabela 3.2 - Registro das leituras executadas com o piezômetro e medidor do nível da água.

Tabela 3.3 - Cotas piezométricas registradas durante o processo de escavação.

75

Tabela 3.4 - Cronograma de avanço da escavação.

77

Tabela 3.5 - Peso específico de solos argilosos 80

Tabela 3.6 - Peso específico de solos arenosos 80

Tabela 3.7 - Correlação para solos não coesivos entre Dr, compacidade e $\mathrm{N}_{\mathrm{SPT}, 60 \text {. }} 83$

Tabela 3.8 - Propriedades comuns de solos não coesivos 83

Tabela 3.9 - Propriedades comuns de solos argilosos 84

Tabela 3.10 - Parâmetros mecânicos do solo 88

Tabela 3.11 - Parâmetros geotécnicos da argila utilizados na modelagem numérica, apresentados por Lima (2007). 89

Tabela 3.12 - Parâmetros dos solos, apresentados por Teixeira. $\quad 91$

Tabela 3.13 - Valores típicos de parâmetros geotécnicos 91

Tabela 3.14 - Valores médios de permeabilidade para vários tipos de solo

92

Tabela 3.15 - Valores típicos de módulo de elasticidade para os solos e rochas

Tabela 3.16 - Valores típicos do coeficiente de Poisson para solos e rochas

Tabela 3.17 - Valores dos parâmetros geotécnicos para o material aterro, de acordo com as fontes bibliográficas de referência.

Tabela 3.18 - Valores dos parâmetros geotécnicos para a argila mole, de acordo com as fontes bibliográficas de referência.

Tabela 3.19 - Valores dos parâmetros geotécnicos para a argila arenosa, de acordo com as fontes bibliográficas de referência. 
Tabela 3.20 - Valores dos parâmetros geotécnicos para o silte arenoso, de acordo com as fontes bibliográficas de referência.

Tabela 3.21 - Parâmetros das camadas de solo do perfil geotécnico

Tabela 3.22 - Elemento placa, representando o concreto projetado (modelo 3D)

Tabela 3.23 - Elemento placa, representando o concreto projetado (modelo 2D)

Tabela 3.24 - Elemento placas, representando o tramo ancorado (bulbo) do tirante (modelo 2D)

Tabela 3.25 - Elementos solido, representando elementos estruturais (modelo 2D e 3D)

Tabela 3.26 - Elemento mola, representando tramo de comprimento livre do tirante (modelo 2D)

Tabela 3.27 - Elemento mola, representando o tramo de comprimento livre do tirante (modelo 3D)

Tabela 3.28 - Elemento estaca, representando o tramo ancorado (bulbo) do tirante (modelo 3D)

Tabela 4.1 - Leituras piezométricas por instrumentação e por análise $2 \mathrm{D}$ e 3D. 


\section{Lista de símbolos}

1/K Coeficiente de compressibilidade

A Área da seção transversal do elemento estaca, do elemento tirante.

B

Matriz derivada da função de forma, função de forma de deformações.

$\mathrm{c}$

Parâmetro de resistência ao cisalhamento, coesão.

c' Parâmetro de resistência ao cisalhamento drenada (tensão efetiva)

$\mathrm{c}_{\mathrm{c}} \quad$ Índice de compressão virgem.

CH Argilas inorgânicas de alta plasticidade

Parâmetro de cambio de permeabilidade durante o processo de

$c_{k}$ adensamento.

$\mathrm{c}_{\mathrm{r}} \quad$ Índice de recompressão do solo.

$\mathrm{c}_{\mathrm{s}} \quad$ Índice de expansão

$\mathrm{c}_{\mathrm{v}} \quad$ Coeficiente de adensamento vertical.

$\mathrm{c}_{\mathrm{w}} \quad$ Adesão sem drenagem entre a parede e o solo

$\mathrm{c}_{\alpha} \quad$ Coeficiente de compressão secundaria.

D Zona de influência dos recalques

D Diâmetro do bulbo para determinação da permeabilidade no campo.

D Matriz de rigidez elástica

D Injeção do ligante por via seca.

D $^{\text {ep }} \quad$ Matriz de rigidez elastoplástica.

$\mathrm{d}_{\mathrm{eq}} \quad$ Espessura equivalente da placa

$\mathrm{D}_{\mathrm{r}} \quad$ Densidade relativa.

e Índice de vazios

E Modulo de elasticidade, modulo de Young

e Espessura da parede de contenção.

E Misturado profundo próximo da parte útil da perfuração

E' Modulo de Young efetivo

$\mathrm{e}_{0} \quad$ Índice de vazios inicial

$\mathrm{E}_{0} \quad$ Módulo elástico tangente, módulo de deformação inicial. 
$\mathrm{E}_{1}$

$\mathrm{E}_{2}$

$\mathrm{E}_{50}$

EA

$\mathrm{EA}_{1}$

$\mathrm{EA}_{2}$

$\mathrm{e}_{\mathrm{cs}}$

EI

$\mathrm{E}_{\mathrm{u}}$

$\mathrm{E}_{\mathrm{ur}}$

F

F

F

$\mathrm{f}(\boldsymbol{\sigma})$

$F_{b}$

$\mathrm{F}_{\mathrm{c}}$

$\mathrm{F}_{\max }$

$\mathrm{F}_{\max , \mathrm{comp}}$

$\mathrm{F}_{\text {max,tens }}$

Fy

$F_{w}$

G

$\mathrm{g}(\boldsymbol{\sigma})$

$\mathrm{G}_{12}$

$\mathrm{G}_{13}$

$\mathrm{G}_{23}$

$\mathrm{G}_{\mathrm{s}}$
Módulo de Young na primeira direção axial, para elementos placa 3D.

Módulo de Young na segunda direção axial, para elementos placa 3D.

Módulo de deformação secante a 50\% da resistência de compressão.

Rigidez axial num elemento placa.

Rigidez normal num elemento placa.

Rigidez na direção de saída do plano

Índice de vazios na condição de estado crítico para $\mathrm{p}^{\prime}=1,0$

Rigidez à flexão.

Módulo de elasticidade não drenado.

Módulo de descarga-recarrega.

Vetor das forças nodais

Coeficiente de segurança.

Fator característico para determinar permeabilidade no campo.

Função de escoamento

Coeficiente de segurança contra o levantamento do fundo.

Força de resistência ao cisalhamento ao longo do plano de deslizamento BT.

Máxima força permitida na ponta da estaca incorporada.

Força de compressão máxima limite, em elementos mola.

Força de tensão máxima limite, em elementos mola.

Fluência do aço

Força de resistência ao cisalhamento no plano de interface entre o solo e o muro, $\mathrm{AB}$.

Módulo de cisalhamento

Função potencial plástica

Módulo de cisalhamento no plano.

Módulo de cisalhamento fora do plano, relacionado com a deformação de cisalhamento através da primeira direção.

Módulo de cisalhamento fora do plano, relacionado com a deformação de cisalhamento sobre a segunda direção.

Massa especifica das partículas sólidas 


\begin{tabular}{|c|c|}
\hline $\mathrm{G}_{\mathrm{u}}$ & Módulo de cisalhamento não drenado. \\
\hline $\mathrm{h}$ & Espaçamento vertical médio das escoras \\
\hline $\mathrm{h}$ & Carga total. \\
\hline $\mathrm{H}, \mathrm{h}$ & Altura, profundidade \\
\hline$h_{0}$ & Profundidade da zona de tração \\
\hline$h_{e}$ & Carga de elevação \\
\hline$h_{p}$ & Carga de pressão \\
\hline$h_{\mathrm{v}}$ & Carga de velocidade \\
\hline I & Momento de inercia à flexão. \\
\hline I & Inclinômetro de controle \\
\hline i & Gradiente hidráulico. \\
\hline $\mathrm{k}$ & Fator de correção de cisalhamento, num elemento placa. \\
\hline K & Modulo volumétrico, modulo de deformação volumétrica. \\
\hline $\mathrm{K}^{\prime}$ & Modulo volumétrico do esqueleto do solo \\
\hline $\mathrm{K}_{\mathrm{a}}$ & Coeficiente de empuxo ativo \\
\hline $\mathrm{K}_{\mathrm{p}}$ & Coeficiente de empuxo passivo \\
\hline $\mathrm{K}_{0}$ & Coeficiente de empuxo no repouso \\
\hline $\mathrm{K}_{0 \mathrm{x}}$ & Coeficiente de empuxo no repouso na direção $x$ \\
\hline $\mathrm{K}_{0 \mathrm{y}}$ & Coeficiente de empuxo no repouso na direção y \\
\hline $\mathrm{K}_{\text {air }}$ & Módulo volumétrico do ar. \\
\hline $\mathrm{k}_{\mathrm{h}}, \mathrm{k}_{\mathrm{v}}$ & Coeficientes de permeabilidade nas direções horizontal e vertical. \\
\hline $\mathrm{K}_{\mathrm{n}}, \mathrm{K}_{\mathrm{t}}$ & $\begin{array}{l}\text { Rigidezes normais elásticas dos elementos da interface incorporados } \\
\text { de um elemento estaca. }\end{array}$ \\
\hline $\mathrm{k}_{\mathrm{rel}}$ & Permeabilidade relativa \\
\hline $\mathrm{K}_{\mathrm{s}}$ & Rigidez de cisalhamento elástico, em elementos estaca \\
\hline $\mathrm{K}_{\mathrm{u}}$ & Módulo volumétrico não drenado. \\
\hline $\mathrm{K}_{\mathrm{w}}$ & Modulo volumétrico da água \\
\hline $\mathrm{K}_{\mathrm{w}, \mathrm{ref}} / \mathrm{n}$ & Rigidez volumétrica de referência corresponde do fluido dos poros \\
\hline $\mathrm{K}_{\mathrm{w}}{ }^{0}$ & Rigidez volumétrica real da água pura. \\
\hline $\mathrm{k}_{\mathrm{x}}, \mathrm{k}_{\mathrm{y}}, \mathrm{k}_{\mathrm{z}}$ & Coeficiente de permeabilidade na direção x, y e z. \\
\hline $\mathrm{L}$ & $\begin{array}{l}\text { Comprimento do bulbo para determinação da permeabilidade no } \\
\text { campo. }\end{array}$ \\
\hline LL & Limite de liquidez \\
\hline
\end{tabular}



LP Limite de plasticidade
$\mathrm{m}_{\mathrm{v}} \quad$ Coeficiente de compressibilidade volumétrica
M
Número de elementos escavados que compartilham um ponto nodal no contorno da escavação.
M Inclinação da linha do estado crítico (LEC) no plano p’ x q.
$\mathrm{M}_{\mathrm{p}} \quad$ Máximo momento de flexão, para comportamento elástico num elemento placa.
$\mathrm{N} \quad$ Força axial num elemento mola.
n Porosidade do solo.
$\mathrm{N}_{\mathrm{p}} \quad$ Máxima força normal, para comportamento elástico num elemento placa.
$\mathrm{N}_{\mathrm{SPT}} \quad$ Índice de resistência à penetração
$\mathrm{N}_{\mathrm{SPT}, 60} \quad$ Valor de $\mathrm{N}_{\mathrm{SPT}}$ corrigido para $60 \%$ da energia teórica de queda livre.
$\varnothing \quad$ Diâmetro
OCR Razão de pré-adensamento
$\mathrm{OH} \quad$ Argilas orgânicas de média e alta plasticidade
P Força sob a parede de contenção
p' Tensão efetiva média, tensão efetiva volumétrica, tensão efetiva isotrópica.
p Tensão média, tensão volumétrica, tensão isotrópica.
p' ${ }_{0} \quad$ Pressão de sobrecarga efetiva
$\mathrm{p}^{\prime}{ }_{0} \quad$ Tensão efetiva media inicial
$\mathrm{p}_{\mathrm{f}} \quad$ Tensão efetiva media na ruptura
$\mathrm{p}_{0} \quad$ Tensão media inicial
$\mathrm{p}_{\mathrm{e}} \quad$ Pressão exterior conformado por pressões de terra
$\mathrm{p}_{\mathrm{f}} \quad$ Tensão media na ruptura
$\mathrm{P}_{\mathrm{A}} \quad$ Empuxo ativo sobre a parede
$\mathrm{P}_{\text {ha, }}, \mathrm{P}^{\prime}{ }_{\text {ha }} \quad$ total e efetivo.
$\mathrm{P}_{\mathrm{hp}}, \mathrm{P}_{\mathrm{hp}} \quad$ Componente horizontal da força passiva total e efetiva, empuxo passivo total e efetivo.
Pt Turfa
$\mathrm{P}_{\mathrm{w}} \quad$ Empuxo lateral devido à agua na fenda de tração 
Tensão desviadora.

$\mathrm{q}_{\mathrm{p}}$ Fluxo nos contornos.

$\mathrm{q}_{\mathrm{x}}, \mathrm{q}_{\mathrm{y}}, \mathrm{q}_{\mathrm{z}} \quad$ Fluxo por unidade de volume nas direções $\mathrm{x}, \mathrm{y}$ e $\mathrm{z}$.

$r_{\text {ext }}$

$\mathrm{r}^{\mathrm{i}-1}$

$\mathrm{R}$

$\mathrm{R}_{\text {inter }}$

$r_{m}$

$\mathrm{S}$

$\mathrm{S}_{\mathrm{u}}$

$\mathrm{t}$

$\mathrm{T}$

$\mathrm{T}_{\max }$

$t_{n}, t_{t}$

$\mathrm{t}_{\mathrm{s}}$

$\mathrm{u}$

$\mathrm{u}_{\mathrm{x}}, \mathrm{u}_{\mathrm{y}}, \mathrm{u}_{\mathrm{z}}$

u e v

$\mathrm{u}_{0}$

$\mathrm{u}_{\mathrm{e}}$

$\mathrm{u}^{\mathrm{p}}$

$u^{\mathrm{s}}$

$\mathrm{u}_{\mathrm{ss}}$

$u_{\mathrm{t}}$

$\mathrm{v}$

$\mathrm{V}_{0}$

$\mathrm{V}_{\mathrm{t}}$

$\mathrm{V}_{\mathrm{s}}$

$\mathrm{V}_{\mathrm{w}}$

$\mathrm{v}_{\mathrm{x}}, \mathrm{v}_{\mathrm{y}}, \mathrm{v}_{\mathrm{z}}$

W

W

$\mathrm{X}_{\min }$
Raio exterior da parede

Vector de força residual

Força de reação do solo

Fator de redução de resistência da interface

Raio médio da parede.

Grau de saturação

Resistência ao cisalhamento não drenado (tensão total)

Tempo decorrido

Fator tempo, para porcentagem média de adensamento $=95 \%$

Máxima tração permitida na superfície da estaca incorporada.

Tensões normais, num elemento estaca.

Força de cisalhamento na direção axial, num elemento estaca.

Poropressão, pressão neutra.

Graus de liberdade de translação

Deslocamentos no plano em direções perpendiculares

Poropressão permanente

Excesso de poropressão.

Deslocamento da estaca, do elemento estaca incorporado.

Deslocamento do solo, do elemento estaca incorporado.

Poropressão de percolação permanente.

Poropressão no instante t.

Valores nodais dos deslocamentos.

Volume do elemento solo em condições naturais.

Volume do elemento solo no instante t.

Massa de solo movimentada lateralmente

Volume de água no interior do elemento de solo.

Componentes da velocidade v, nas direções $\mathrm{x}, \mathrm{y}$ e $\mathrm{z}$

Teor de umidade

Peso do solo na cunha

Condição de contorno na direção x menor, no modelo em 3D. 


\begin{tabular}{|c|c|}
\hline $\mathrm{y}_{\min }$ & Condição de contorno na direção y menor, no modelo em 3D. \\
\hline $\mathrm{z}_{\min }$ & Condição de contorno na direção z menor, no modelo em 3D. \\
\hline$\alpha$ & Ângulo do plano de ruptura \\
\hline$\alpha$ & $\begin{array}{l}\text { Parâmetro utilizado como interruptor, entre material elástico e } \\
\text { plástico. }\end{array}$ \\
\hline$\beta$ & Ângulo da inclinação superficial \\
\hline$\gamma$ & Peso específico \\
\hline$\gamma_{\text {sat }}$ & $\begin{array}{l}\text { Peso específico saturado; aplica-se a todo material que esta abaixo } \\
\text { do lençol freático. }\end{array}$ \\
\hline$\gamma_{\text {unsat }}$ & $\begin{array}{l}\text { Peso específico não saturado; aplica-se a todo material que esta } \\
\text { acima do lençol freático. }\end{array}$ \\
\hline$\delta$ & Incrementos \\
\hline$\Delta$ & Incrementos \\
\hline$\delta$ & Ângulo de atrito da parede, entre o solo e a parede \\
\hline$\delta_{\mathrm{a}}$ & Deslocamento correspondente a pressões de terra ativas \\
\hline$\Delta \mathrm{f}_{\mathrm{u}}$ & Incremento do vetor \\
\hline$\delta_{\mathrm{H}}$ & Deslocamento lateral horizontal de uma parede \\
\hline$\delta_{\mathrm{H}(\max )}$ & Deslocamento lateral horizontal máximo da parede de contenção. \\
\hline$\delta_{\mathrm{p}}$ & Deslocamento correspondente a pressões de terra passivas \\
\hline$\Delta \mathrm{t}$ & Passo de tempo \\
\hline$\Delta \mathrm{u}$ & Excesso de poropressão. \\
\hline$\Delta \mathrm{u}_{\mathrm{f}}$ & Excesso de poropressão na ruptura. \\
\hline$\Delta \mathrm{u}_{\mathrm{t}}$ & Excesso de poropressão no instante $\mathrm{t}$. \\
\hline$\delta_{\mathrm{V}}$ & Recalque do terreno \\
\hline$\delta_{\mathrm{V}(\max )}$ & Recalque máximo do terreno \\
\hline$\Delta \mathrm{V}_{\mathrm{t}}$ & Incremento do volume do corpo no instante $t$ \\
\hline$\theta$ & Ângulo da inclinação posterior da parede \\
\hline$\varepsilon_{\mathrm{a}}$ & Deformação axial \\
\hline$\varepsilon^{\mathrm{e}}, \varepsilon^{\mathrm{p}}$ & $\begin{array}{l}\text { Vetor com componentes de deformação cartesianas elásticas e } \\
\text { plásticas, componentes normais. }\end{array}$ \\
\hline$\varepsilon_{\mathrm{N}}$ & Deformação normal, num elemento estaca \\
\hline$\varepsilon^{\mathrm{p}}$ & Vetor de deformação plástica \\
\hline$\varepsilon_{\mathrm{p}}$ & Deformação volumétrica \\
\hline
\end{tabular}




\begin{tabular}{|c|c|}
\hline$\varepsilon_{\mathrm{q}}$ & Deformação distorcional, deformação cisalhante \\
\hline$\varepsilon_{\mathrm{r}}$ & Deformação radial \\
\hline$\varepsilon_{\mathrm{V}}$ & Deformação volumétrica \\
\hline$\kappa$ & $\begin{array}{l}\text { Inclinação da linha de descarregamento/recarregamento, no plano e } \\
-\ln \left(p^{\prime}\right)\end{array}$ \\
\hline$\lambda$ & $\begin{array}{l}\text { Inclinação da linha virgem ou linha de adensamento isotrópica } \\
\text { (LCI) e linha do estado crítico (LEC), no plano e }-\ln \left(\mathrm{p}^{\prime}\right)\end{array}$ \\
\hline$\lambda$ & Multiplicador plástico \\
\hline$\mu$ & $\begin{array}{l}\text { Multiplicador escala que define o mecanismo de deformação } \\
\text { plástica }\end{array}$ \\
\hline$v$ & Coeficiente de Poisson \\
\hline$v^{\prime}$ & Coeficiente de Poisson para carregamento drenado \\
\hline$v_{12}$ & Coeficiente de Poisson no plano 12. \\
\hline$v_{\mathrm{u}}$ & Coeficiente de Poisson para carregamento drenado \\
\hline $\boldsymbol{\sigma}$ & $\begin{array}{l}\text { Vetor com componentes de tensão cartesianas, componentes } \\
\text { normais. }\end{array}$ \\
\hline $\begin{array}{l}\sigma_{\mathrm{xx}}, \sigma_{\mathrm{yy}}, \sigma_{\mathrm{zz}} \\
\tau_{\mathrm{xy}}, \tau_{\mathrm{yz}}, \tau_{\mathrm{zx}}\end{array}$ & Componentes de tensão do estado de tensão num ponto, no espaço. \\
\hline$\sigma, \sigma^{\prime}$ & Tensão normal total e efetiva \\
\hline$\sigma_{1}^{\prime}, \sigma_{2}^{\prime}, \sigma_{3}^{\prime}$ & Tensões principais efetivas. \\
\hline$\sigma_{\mathrm{a}}^{\prime}$ & Tensão efetiva axial \\
\hline$\sigma_{\mathrm{c}}^{\prime}$ & Tensão confinante efetiva, pressão de adensamento isotrópico. \\
\hline$\sigma_{r}^{\prime}$ & Tensão efetiva radial \\
\hline$\sigma_{h}^{\prime}$ e $\sigma^{\prime}$ & Tensão horizontal e vertical efetiva \\
\hline$\sigma_{\mathrm{v} 1}^{\prime}$ & Tensões verticais efetivas \\
\hline$\sigma_{\mathrm{v} 0}^{\prime}$ & Tensão efetiva vertical no campo. \\
\hline$\sigma_{x}^{\prime}, \sigma_{y}^{\prime}$ & $\begin{array}{l}\text { Componentes de tensão efetivas do estado de tensão num ponto no } \\
\text { plano. }\end{array}$ \\
\hline$\sigma_{0}$ & Tensão horizontal total no campo \\
\hline$\sigma_{1}, \sigma_{2}, \sigma_{3}$ & Tensões principais totais. \\
\hline$\sigma_{\mathrm{f}}$ & Vetor da tensão de escoamento. \\
\hline$\sigma_{\mathrm{h},} \sigma_{\mathrm{v}}$ & Tensão horizontal e vertical total. \\
\hline$\sigma_{\text {ha }}, \sigma_{\text {ha }}$ & Pressão de terra ativa total e efetiva \\
\hline
\end{tabular}




$\begin{array}{ll}\sigma_{\mathrm{hp}}, \sigma^{\prime}{ }_{\mathrm{hp}} & \text { Pressão de terra passiva total efetiva } \\ \sigma_{\mathrm{med}} & \text { Tensão de compressão média } \\ \sigma_{\mathrm{t}} & \text { Tensão de tração disponível } \\ \sigma_{\mathrm{x} 0}, \sigma_{\mathrm{y} 0}, \tau_{\mathrm{xy} 0} & \text { Tensões vertical, horizontal e de cisalhamento iniciais. } \\ \tau & \text { Tensão cisalhante } \\ \tau_{\mathrm{f}} & \text { Tensão cisalhante de pico } \\ \phi & \text { Parâmetro de resistência ao cisalhamento, ângulo de atrito. } \\ \phi & \text { Parâmetro de resistência ao cisalhamento drenada (tensão efetiva) } \\ \phi_{\mathrm{u}} & \text { Parâmetro de resistência ao cisalhamento não drenada (tensão total) } \\ \phi_{\mathrm{x}}, \phi_{\mathrm{y}}, \phi_{\mathrm{z}} & \text { Graus de liberdade de rotação. } \\ \psi & \text { Ângulo de dilatação }\end{array}$




\section{Lista de Abreviaturas}

CD Ensaio de compressão triaxial drenado convencional

CID Ensaio adensado isotropicamente drenado

CIU Ensaio adensado isotropicamente não drenado

CRS Ensaio de adensamento com velocidade de deformação controlada.

DSM Métodos de misturado profundo do solo.

J

Misturado do ligante com o solo com sistema de jatos de argamassa de alta velocidade tipo jet grouting.

MC Modelo Mohr-Coulomb.

P Piezômetro de tubo aberto, piezômetro de controle.

PS Poço de serviço

$\mathrm{R}$

Misturado do ligante com o solo, mediante rotação de laminas ou hélices.

S

Misturado profundo em forma continua ao longo da tubulação de perfuração, por médio de laminas ou hélices.

SIC Ensaio de adensamento convencional com carregamento incremental.

SP Sondagens de reconhecimento SPT

SS Modelo Soft-Soil

SSC Modelo Soft-Soil-Creep

UU Ensaio não adensado não drenado.

W Injeção do ligante por via úmida 